\title{
Communication as the crucial aspect of collaboration among three established medical schools in Indonesia: curriculum evaluation process
}

\author{
Ardi Findyartini ${ }^{1}$, Estivana Felaza ${ }^{1}$, Diantha Soemantri ${ }^{1}$, FX Bambang Sakiman ${ }^{2}$, Aswiyanti ${ }^{3}$, \\ Erly Indrama ${ }^{3}$
}

\begin{abstract}
Aligned with the effort to increase and maintain the quality of medical institutions, three wellestablished schools of medicine in Indonesia formed a collaboration framework comprising areas of medical education, research, and services. The undergraduate medical curriculum was identified as one of the main areas for collaboration, with curriculum evaluation as the first step taken. This article emphasizes the reflection of each institution on the collaboration process. The focuses were on the positive impacts, disadvantages or negative impacts, obstacles and solutions for further improvement in the collaboration. Semi-structured interviews with each faculty leader and collaborator were conducted to obtain a comprehensive view of the current collaboration process. Although some advantages resulting from the collaboration were widely acknowledged, many obstacles were also identified. Ineffective communication between and within each collaborating institution became one of the potential hurdles in the process of collaboration. Despite the obstacles in collaborating, the stakeholders involved felt the benefits of the process, in which each institution was encouraged to review the existing curriculum and evaluation program, identify any weaknesses and determine further plans.
\end{abstract}

Key words: collaboration, curriculum evaluation, effective communication

\section{Introduction}

There has been a rapid and extensive growth of medical schools in the world, with over 19,000 medical schools in six of the seven continents. Little is known however on the quality and medical curriculum implementation in most of the medical schools, except for selected countries and regions (Boulet et al., 2007).

\footnotetext{
${ }^{1}$ Faculty of Medicine, Universitas Indonesia, Jakarta

${ }^{2}$ Faculty of Medicine, Universitas Sebelas Maret, Surakarta

${ }^{3}$ Faculty of Medicine, Universitas Andalas, Padang

Corresponding author:

Ardi Findyartini, MD, PhD

Faculty of Medicine, Universitas Indonesia

Salemba 6, Central Jakarta, 10430

E mail: findyartini@yahoo.com
}

Indonesia as one of the most populous countries, was reported to have 35 active medical schools based on the International Medical Education Directory (IMED) and Avicenna directories (formerly WHO World Directory of Medical Schools) listing in November 2011. At present there are 72 state and private medical schools in Indonesia. This development was encouraged by an incline in the provincial autonomy and the need to overcome the medical doctor distribution problem in Indonesia. Despite the rationale of medical school development, a systematic effort is required to increase and maintain the quality of these medical schools. Currently, only $50 \%$ of medical schools in Indonesia are recognized internationally, and among the rest, many have not been accredited by the national accreditation body.

Faculty of Medicine, Universitas Indonesia (FMUI) in Jakarta, Faculty of Medicine, Universitas Andalas (FM UNAND) in Padang, West Sumatra, and Faculty of Medicine 
Universitas Sebelas Maret (FM UNS) in Surakarta, Central Java are three wellestablished schools of medicine in Indonesia located in three different regions. These three institutions have been involved in the development of a collaboration framework comprising areas of medical education, medical research and medical services.

\section{Theoretical framework}

The spirit of collaboration may be based on several convictions, such as humanitarian reasons, educational benefits, financial benefits and also reputation enhancement (Kanter, 2010). Some outstanding collaborations in several institutions can be highlighted. The Medical School for International Health (MSIH) was a collaboration between the Ben Gurion University of Health Sciences (BGU) in BeerSheeva, Israel and Columbia University Medical Center (CUMC) located in New York City, USA (Margolis et al., 2004). Page et al. (2008) reported a joint program between 3 medical institutions in Australia: University of Western Sydney, University of Wollongong, and University of Sydney. Furthermore, Corbie-Smith et al. (2010) from University of North Carolina reported collaboration between the institution with Duke University and members of Latino community in North Carolina to develop a lay health advisor program to improve Latina immigrants' mental health and coping skills. On these exemplary collaborations, obstacles were met and strategies to overcome those obstacles were implemented. Among the major obstacles identified were communication issues, especially for collaborators that geographically separated from one another.

Steps taken to launch the collaboration can initiate from clearly defining the tasks of each institution. The second step is establishing an organizational structure in each institution for accomplishing these aforementioned tasks. The third step is to ensure clear communication between the collaborating institutions. The fourth step is to define specific outcomes to measure success and evaluate the program continuously. Problems arise from institutions' perspective as well as the students', need to be addressed accordingly. This final step of analysing problems and developing solutions for each problem is very much needed to ensure the sustainability of the collaboration (Margolis, 2004; Page et al., 2008; Corbie-Smith et al., 2010).

\section{Steps taken in the collaboration process on the curriculum development of the three medical institutions}

Undergraduate curriculum development was the first area of collaboration of the three institutions. Curriculum development comprises several inter-related steps (Kern et al., 1998). Each institution has developed a competency based medical education for its undergraduate training based on the Indonesian National Standard of Competency for Medical Doctors (Faculty of Medicine Universitas Indonesia, 2005; Faculty of Medicine Universitas Andalas, 2004; Faculty of Medicine Universitas Sebelas Maret, 2007). In addition, the integrated approach as a part of the SPICES - Student Centred, Problem Based, Integrated, Community Based, Elective, Systematic - educational strategy (Harden et al., 1984) has been implemented in the three institutions. Given the existing undergraduate medical curricula, the collaboration on curriculum development was started by conducting a curriculum evaluation process.

\section{Identification of the collaboration area on curriculum evaluation}

It was identified from the first collaboration meeting that curriculum evaluation in each institution was as yet to be well established. Therefore, several collaboration areas on curriculum evaluation were identified. As defined in the literature, the first step to start collaborating is to clearly define the tasks of each institution (Margolis, 2004; Page et al., 2008; Corbie-Smith et al., 2010).

Therefore, in the FM UI - FM UNAND - FM UNS collaboration program, the first task was to analyse the curriculum development and evaluation process of each institution and to determine the areas for collaboration. The selection was based on several factors, which include the importance, available funding, human resources and feasibility. A working plan was developed for each area and the responsibility of each person from each institution involved in the work was described as clearly as possible.

The following were identified as the areas of collaboration in curriculum evaluation: educational environment measurement using DREEM (Dundee Ready Education Environment Measure) (Roff et al., 1997; Soemantri et al., 2008) and PHEEM (Postgraduate Hospital Education 
Environment Measure) (Roff et al., 2005) for Kirkpatrick (Kirkpatrick \& Kirkpatrick, 2006) level 1 evaluation, collaborative progress testing, comprehensive examination and external examiners exchange for level 2 evaluation, and also the internship program evaluation. The internship program evaluation cannot be fully accounted for level 3 evaluation. However, at the moment that particular evaluation is considered to be the only evaluation method that is feasible for Kirkpatrick level 3 evaluation. The last area of collaboration is the completion of Asian University Network (AUN) (Asian University Network, 2011) certification forms as an exercise for each institution, prior to starting the formal regional process by AUN. Each institution would also serve as an informal assessor for another institution, in order to strengthen the capacity of each institution in conducting the internal quality assessments and facing the external quality assurance system.

\section{Methods}

\section{Reflection on the process}

A semi-structured interview was conducted in the three institutions to obtain some perceptions of those who have been directly involved in curriculum evaluation collaboration, based on their reflections upon that particular process. The interviewees were selected purposively. It was aimed to obtain a comprehensive perception of the collaboration process from informants who were closely involved in the collaboration and from those who were not. This included the collaboration project leader, deanery, Medical Education Unit, Department of Medical Education members and academic staff from each institution. The interview questions include perceptions on advantages and disadvantages of the collaboration process on curriculum evaluation as well as challenges and suggested solutions. A total of 26 interviews were completed ( 1 collaboration project leader from Ministry of Education, 8 in FM UI, 6 in FM UNAND and 11 in FM UNS). The transcriptions were made verbatim. These transcriptions were then analysed manually using a thematic analysis technique by two authors at FM UI (AF, EF), two authors at FM UNAND (AA, EI) and one author at FM UNS (BS). Further data analyses were conducted in two steps in one face-to-face meeting: analysis of data from each institution and comparison of data from the three institutions to elaborate similarities and differences. The conduct of this preliminary research was aligned with research ethics of the three institutions.

\section{Results}

\section{Reflection on the collaboration of undergraduate curriculum evaluation}

The reflection can be categorized into four areas of collaboration on the curriculum evaluation: positive impact, disadvantage or negative impact, hurdles, and offered solution for further improvement.

Positive impact of collaboration on the curriculum evaluation

There was a strong agreement that collaborative activities on curriculum evaluation provided insightful information and constructive feedback for each institution. By sharing information on what had been planned and implemented in each curriculum, the three institutions had opportunity to learn collaboratively.

"Through collaboration, each institution has opportunities to share about the curriculum and obtain feedback from the other two institutions. Having this process, [we] obtained a lot of lessons to improve situation [in each institution]." (SA-UNAND-collaborator)

More importantly, strongly agreed by all interviewees, the highlight of the collaboration process was on the opportunity of curriculum benchmarking and of fostering the curriculum improvement in each institution. For instance, one area of agreement in this collaboration of curriculum evaluation was for each institution to develop a curriculum evaluation blueprint. The 'collaboration assignment' forced the responsible units or stakeholders to evaluate the current process, integrate the evaluation data, and develop the curriculum evaluation blueprint.

"We are encouraged to review the process and program [in our institution].... and [we are also encouraged] to analyse our condition and think about how this collaboration contributes to our curriculum improvement."(SD-UIcollaborator)

Negative impact of collaboration on the curriculum evaluation

Despite the strong agreement on the benefit, most interviewees also identified the negative impact of the collaboration. Six out of nine interviewees from FM UI underscored that the 
collaboration activities increased their workload to a great extent, and this further influenced their focus in accomplishing routine assignments.

"This collaboration process is relatively new and it is really time and labour consuming. Sometimes the [activities conducted] in collaboration are not [fully] efficient and they interrupt routine activities in each institution." (SI-collaboration project leader)

Most interviewees however were having trouble in elaborating the negative impact of this collaboration because they considered that the collaboration should only aim at providing positive impacts. One interviewee said that the increase of the workload should not become a negative impact if all parties involved in the collaboration activities committed to the schedule and agreed targets.

Obstacles of collaboration on the curriculum evaluation

Several obstacles in the collaboration process were identified by most interviewees. This included imbalanced workload, ineffective internal and external communication, ineffective face-to-face meeting and unsystematic scheduling.

First, as described in the previous theme, the imbalanced workload led to extra work for certain parties to fulfil the collaboration target. This was perhaps because the collaboration targets were not determined by considering the capability of each collaborating institution. It was realized however that it was challenging to synchronize all collaboration activities with each institution's need. It was also emphasized by collaborators from FM UNAND and UNS that those who were involved as collaborators had also been assigned to other tasks in each institution. This might influence the fulfilment of collaboration targets. The imbalanced workload may also reflect an unequal commitment to the collaboration process. This however was argued by an interviewee as follows:

"The unequal commitment perhaps does not always reflect that some parties commit but some others don't. [What happened] probably that the commitment is there already, but not devoted at the same time. Collaboration is hard because [we need to] have the same commitment at the same time, and it does not always happen." (CN-Ul-faculty leader, collaborator)
A further hurdle identified by academic staff directly involved in the collaboration activities and the deanery member was communication problems. The deanery member felt that there was no adequate update of information from the collaborators. This could be seen as an internal communication problem.

"Actually when I missed the [face-to-face] meetings, I would not know what was happening in the collaboration process." (SPUl- faculty leader)

The academic staff involved in the collaboration also sometimes noticed ineffective communication among the three institutions, for example in long distance communication via email. In addition to the internal and external communication, the collaborators also identified inefficient face-toface meeting that was probably a culmination of other problems identified previously.

\section{Offered solution for further improvement}

Solutions were offered for further improvement in the collaboration process. Unsurprisingly, the solutions were strongly related to the identified problems. The first and most important solution was the improvement of the internal and external communication.

"We might want to have a website where the update of collaboration activities can be uploaded. This way all activities completed by each institution can be directly updated. Also, presentation of the progress report should be conducted in front of the faculty leaders and collaborators. Because actually the collaboration activities most of the time were the results of discussion of collaborators, and they were not necessarily communicated well to the faculty leaders. Consequently, any problems such as budgeting of the activities cannot be rectified as soon as possible." (SP. UI- faculty leader)

"Mailing list can be utilized, in order to keep each collaborator well-informed even though they cannot attend each meeting"(AA-UNANDfaculty leader, collaborator)

Issues on limited resources of both staff and funding were addressed by suggesting mapping of faculties involved in the collaboration activities and strategies for effective funding.

"[We need] better management of staff members" (FM-UNS-collaborator) 
Another solution offered was by involving other institutions in order to learn from their experiences.

\begin{abstract}
"We can involve resource persons from the institution other than the collaborating institutions to share their experiences so that we can learn from them" (AA- UNAND-faculty leader, collaborator)
\end{abstract}

\section{Discussion}

The reflection upon the collaboration process enables the faculty leaders and collaborators to identify the strengths and weaknesses of the process, pinpoint major obstacles and offer possible solutions. The positive impact of collaboration as a learning opportunity identified by the three institutions was shared by all the collaborations stated earlier. Institutions can learn from one another's experience and work together to improve their performance (Kanter, 2010; Margolis, 2004; Page et al, 2008).

The first step of establishing collaboration should be on defining clear tasks of each institution as well as each personnel involved (Kanter, 2010). Careful planning and mutual agreement on the task assigned will hopefully increase the commitment level. Within FMUIUNAND - UNS collaboration, tasks have been planned and assigned, however since most collaborators are also academic staff with routine assignments and responsibilities in their own institutions, the reconsideration of the amount of tasks and target of each task may be worthwhile. It is identified from this preliminary study that increased and imbalanced workload may hinder the benefits of collaboration.

Communication between institutions is also identified as one of the potential problems arising in collaboration. Despite the geographical distance, communication problems can be handled through advancements in technology which enables even distantly located centres to maintain effective communication through telephones, e-mails, fax, and video-conferencing (Kanter, 2010). Since the collaborating institutions are well-established medical faculties, each institution most likely expects equal contributions from its counterparts. However, to achieve equal contributions from the three institutions, it is important to manage an effective communication system. A clear organizational structure and leadership therefore is required to facilitate communication and to determine the role of collaborators and faculty leaders within the collaboration framework. In addition, effective face-to-face and long distance communication will influence the success and effectiveness of the collaboration process. The three prominent examples of collaboration among medical schools also identified the importance of communication as one of the main lessons learned (Margolis et al., 2004; Page et al., 2008; Corbie-Smith et al., 2010).

Despite the problems and obstacles of collaborating, the stakeholders involved feel the benefits of the process. With regards to the curriculum development, there were educational benefits of the collaboration process for each institution given the opportunity to review the existing curriculum, evaluate the program, identify any weaknesses and determine further plans. This is in line with what Kanter (2010) has proposed that educational benefits are one of the underlying reasons of conducting a collaboration program. The reflection upon this UI-UNAND-UNS collaboration program has signalled the need to pay major attention to the communication aspect of collaboration. If not, the negative impacts will outweigh the benefits and each institution will be more reluctant to fully participate. Consequently, the purposes of collaboration will not be accomplished.

This study was not without limitation. It was conducted based on the collaboration of only three well established medical institutions in Indonesia. The benefits, challenges and solutions identified in this study can be very specific to the contexts of the three institutions, the collaboration framework, and the country. Therefore, the transferability to other contexts requires caution. The results however are supported by previous studies highlighting collaboration among higher education institutions.

\section{Conclusion}

Self-reflections from the three collaborating institutions highlight the importance of maintaining good communication within and among the institutions. At the early stage, effective communication among collaborators and faculty leaders is required to get commitments, including commitment from the collaboration project leader. Since collaboration in curriculum evaluation is expected to give benefit and accelerate the improvement process in each institution, 
getting commitment is a must. Furthermore, each collaborating institution needs to set feasible targets for the collaboration activities. Again, communicating and accepting the strengths and limitations of each institution is crucial in order to achieve this.

Finally, any agreed collaboration activities require strong faculty leader support and funding. Academic staff collaborating in various activities need to update the faculty leaders as the decision of 'go-no go' of each activity really depends on them. This emphasizes the need of clear organizational structure and leadership in the collaboration process.

\section{Acknowledgement}

The collaboration is supported by the Directorate General of Higher Education, Ministry of Education and Culture, Republic of Indonesia in the project entitled 'The Development of Medical Education and Research Centre and Two University Hospitals Project in Indonesia'.

\section{References}

Asean University Network (2011) Asean University Network quality assurance: Guide to AUN actual quality assessment at programme level, Bangkok, Thailand: AUN.

Boulet, J., Bede, C., McKinley, D. \& Norcini, J. (2007) An overview of the world's medical schools, Medical Teacher, 29, pp. 20-26.

Corbie-Smith, G., Yaggy, S.D., Lyn, M., Green, M., Ornelas, I.J., Simmons, T., Perez, G. \& Blumenthal, C. (2010) Development of an interinstitutional collaboration to support community-partnered research addressing the health of emerging Latino populations, Academic Medicine, 85, 4, pp.728-735.

Faculty of Medicine Universitas Indonesia (2005) Competency Based 2005 Faculty Curriculum Book, Jakarta, Indonesia.

Faculty of Medicine Universitas Andalas (2004) Faculty Curriculum Book, Padang, Indonesia.
Faculty of Medicine Universitas Sebelas Maret (2007) Faculty Curriculum Book, Surakarta, Indonesia.

Harden, R.M., Sowden, S. \& Dunn, W.R. (1984) Educational strategies in curriculum development: the SPICES model, Medical Education, 18, 4, pp. 284-297.

Kanter, S.J. (2010) Collaboration between medical schools: what are the benefits and risks? Academic Medicine, 85, 10, pp.1547-1548.

Kern, D.E., Thomas, P.A., Howard, D.M.\& Bass, E.B. (1998) Curriculum development for medical education: a six-step approach, Baltimore: The Johns Hopkins University Press.

Kirkpatrick, D.J.\& Kirkpatrick, J.D. (2006) Evaluating training programs: the four levels, 3rd ed. San Francisco: Berrett-Koehler Publishers, Inc.

Margolis, C.Z., Deckelbaum, R.J., Henkin, Y., Baram, S., Cooper, P. \& Alkan, M.L. (2004) A medical school for International Health Run by International Partners, Academic Medicine, 79, 8, pp. 744-751.

Page, S.L., Birden, H.H., Hudson, J.N., Thistlethwaite, J.E., Roberts, C., Wilson, I., Bushnell, J., Hogg, J., Freedman, S.B. \& Yeomans, N. (2008) Medical schools can cooperate: a new joint venture to provide medical education in the Northern Rivers region of New South Wales, Medical Journal of Australia, 188, 3, pp.179-181.

Roff, S., McAleer, S., Harden, R.M., Al-Qahtani, M., Ahmed, A., Deza, H., Groenen, G. \& Pimparyon, P. (1997) Development and validation of the Dundee Ready Education Environment Measure (DREEM), Medical Teacher, 19, 4, pp. 295-299.

Roff, S., McAleer, S. \& Skinner, A. (2005) Development and validation of an instrument to measure the postgraduate clinical learning and teaching educational environment for hospitalbased junior doctors in the UK, Medical Teacher, 27, 4, pp. 326-331.

Soemantri, D., Roff, S. \& McAleer, S. (2008)Students' perceptions of the educational environment in the midst of curriculum changes. Medical Journal of Indonesia, 17, 1, pp. 57-63. 